\title{
SUPPORTING CLEAR: A STRATEGY FOR SMALL AND MEDIUM SIZE ENTERPRISE ADOPTION OF E-BUSINESS PRACTICES IN ATLANTIC CANADA
}

\author{
DAWN JUTLA and TERRANCE WEATHERBEE \\ Faculty of Commerce, Saint Mary's University, Halifax, Nova Scotia, Canada
}

\begin{abstract}
The successful adoption of e-business practices for small and medium sized enterprises involves creating a business environment for an innovation-based economy. The necessary environment does not yet exist in investment-based economies, such as Canada, that depend on natural resource wealth. In Canada, excellence in providing a business environment for the knowledgebased economy is being created in silos amidst a mix of formal and informal efforts at various levels of government. This paper describes university support for CLEAR, an acronym for Coordinated Learning for E-Business Adoption, Research, and Resources, which is a strategy designed to accelerate e-business adoption in SMEs (Small and Medium-sized Enterprises) in Atlantic Canada. Addressing problems such as isolated silos of excellence, poor communications, and non-existent knowledge sharing, mentoring, delivery, and measuring mechanisms for e-business, CLEAR is anchored on a network of strong research collaboration with universities, private and public sector associations, private sector firms, private and public sector institutions and agencies for innovation and value creation. What is novel about CLEAR is that the management of the CLEAR network activities is to be hosted in university business schools versus government agencies, thereby leveraging the research capacities and business expertise in the region. The expected value lies in the aggregation and alignment, of resources, capacities, and capabilities in e-business with the needs of the SME firms.
\end{abstract}

The original version of this chapter was revised: The copyright line was incorrect. This has been corrected. The Erratum to this chapter is available at DOI: 10.1007/978-0-387-35692-1_36 


\section{INTRODUCTION}

According to Michael Porter (2001), more sophisticated strategies by companies require more skilled people, better information, more advanced infrastructure and stronger competitive pressures. More sophisticated strategies for developing an innovation-based economy from governments require much of the same. The business environment for the knowledge economy is created and sustained when at least six types of infrastructure are strategically and tactically addressed: (1) knowledge and innovation, (2) communications and information infrastructure and access (3) regulatory, trust, and financial infrastructure, (4) human infrastructure, (5) egovernment, (6) content (Jutla et al, 2002a, b). Most countries support initiatives to address the fulfillment of the infrastructure pieces (e.g. IEI (2000), IntIsland (2000))

CLEAR is a complementary strategy, initiated in Weatherbee (2000), to accelerate adoption of e-business practices in SMEs in Atlantic Canada thereby helping some businesses to use, and others to create innovation for competitive advantage. CLEAR's strategy builds, through consensus, an innovation network of SMEs, SME associations, local boards of trade, government agencies, provincial governments and municipalities, universities, and regional community colleges. CLEAR adds an integrative layer that enables the multi-disciplines within business to play active roles in creating and sustaining an innovation economy.

Recognizing that the CLEAR strategy is not being formed in a vacuum, required elements include alignment, collaboration, and non-duplication of the partners' existing services and programs that are already deployed, or that are in development. Initiatives to support federal and municipal-level strategies for SME adoption of e-business practices are common in many countries. Universally, we see non-alignment of federal and municipal strategies as they are independently created in parallel. For example, from consultation through interviews, a number of local governments in Canada appear oblivious of federal strategies to promote SME adoption of ebusiness practices. Clearly only minimal efforts are being made to align egovernment strategies in Canada. Superficial evidence is readily apparent by simply surfing the various local municipal web sites and viewing the unpredictability in naming city or municipal sites, inconsistency in formatting content, and non-uniformity of navigation paths (Jutla et al, 2002c). Nonetheless, despite seemingly ad-hoc efforts, Canada was recently acclaimed as a leader in e-government (Accenture 2001). Early successes are more quickly visible in Canada, the second largest country in the world, because of its relatively high level of connectivity but relatively small population of less than 30 million people. Compared with Canada, countries 
like the United States with 10 times the population, and hence scale, require much more formality to show early successes for strategies. However, excellence will only become widespread in Canada if more formal infrastructure and mechanisms are set in place.

This paper outlines support for a strategy advocating formal mechanisms and structure for the acceleration of e-business adoption in SMEs in Atlantic Canada. In turn, the CLEAR strategy is intended to support the federal-level SME adoption initiative. The paper is organized as follows. Section 2 describes federal initiatives to create an innovation-based economy and also the Canadian Roundtable SME e-Business Adoption Initiative. Section 3 explains the Atlantic Canada business environment. Section 4 lists CLEAR's services, and presents the support for the CLEAR strategy. Finally, a summary and concluding remarks are provided in section 5 .

\section{E-BUSINESS READINESS AND SME E- BUSINESS ADOPTION INITIATIVES IN CANADA}

We will examine Canadian advances with reference to the model for creating an e-business readiness climate presented in Jutla et al (2000b). The model proposes that the key infrastructure for country-level e-business readiness lies in: (1) knowledge and innovation processes, (2) communications and information infrastructure and access (3) regulatory, trust, and financial infrastructure, (4) human infrastructure, (5) e-government infrastructure, and (6) content infrastructure.

Knowledge and ability to innovate has strong impact on SMEs (Craig, 2000). Lefebvre and Lefebvre (2000) illustrate how R\&D and knowledge intensity in SMEs are positively related to their export effectiveness suggesting a strong link to job creation potential. In 2000, the OECD highlighted the challenges that SMEs face in industry-science relationships and suggested that governments must help to enhance the ability of national firms, especially SMEs, to partner with public research institutions as well as to access global research networks and markets (Barre and Guinet, 2000). Canada has made several billion Canadian dollars available for the creation of knowledge and innovation through various federal-level research and development funding agencies over the past few years. The Canadian Foundation for Innovation grants, that top universities and researchers in Canada compete for, are provided from a federal billion-dollar fund. Other funding bodies for support of innovation include CANARIE, Canada's 
Advanced Internet Development Organization that in 1998 initiated the first project in the world to create a purely optical-based national network (CANARIE, 2002). Presently, Canada has the world's longest purely optical network at $6000 \mathrm{~km}$ long. According to CANARIE, "CA*net 3 is being used as a model for the next generation of networks in other countries, (CA3, 2002)." In late 1999, Canada was leading the rest of the world in communications infrastructure by almost a year. However, by early 2001, most other countries had leapfrogged to install similar infrastructure with transmission speeds at $2.5 \mathrm{Gbps}$. Canada is reported to have delivered 10 Gbps speeds in 2001. Most networks in the Gbps range are only currently available to universities and research institutions where resident scientists can develop applications of great impact to society. However we are starting to see SMEs being encouraged to collaborate on broadband applications research with universities. For example, CANARIE provides funding for SMEs who want to do research in broadband content applications as well as virtual cluster development. Since the CA*net3 network is not yet available to SMEs, except through research partnerships, Canada's lead in technical infrastructure is not enough to affect the SME economy today, but certainly impacts on their future as dependent innovations are diffused to the business world.

Outreach programs to the SME community are ongoing in the government's communications effort to get the message about e-business practices out. In 2000 and 2001, agencies of Industry Canada conducted dozens of workshops and seminars on e-commerce for the SMEs across Canada. While uptake is good on email and informational marketing web site applications, there is a marked lack of uptake on more sophisticated ebusiness applications such as customer relationship management and content management. Also we see inconsistency on how e-business is defined by local SME associations leading to inconclusive measures of e-business adoption.

Canada has made many advances in establishing information infrastructure, increasing access, and upgrading skills. In terms of access to lower speed communications infrastructure, by March 1999, Canada had connected each school and public library, under the SchoolNet (2002) and LibraryNet initiatives. Through the community access program (CAP, 2002), Canada intends to connect 10,000 communities. The VOLNet (2002) initiative connects a further 10,000 voluntary organizations.

On the regulatory front, Canada's Personal Information Protection and Electronic Documents Act (Bill C-6, 2002) recognizes the equivalence of electronic signatures and documents to their physical counterparts. It also legislates the privacy aspect of security for businesses and their customers. Canada has proposed a Seal of Seals for regulating trust providers. Industry 
Canada provides a support site (www.strategic.ic.gc.ca) that provides details on e-business elements including security. Since 1998 the banking sector and third parties have responded to barrier issues such as expense of credit card processing fees and now offer inexpensive online credit card processing services to merchants. Canadian insurance companies are now designing insurance policies to cover "data and phone bandwidth interruption", and "data integrity insurance", and extended clauses on "good name" insurance to cover web site defamations and negative publicity from security attacks. However these are not ready for Canadian businesses as yet, and probably will not be offered to SMEs for almost another year.

On a national level, SMEs are asking for leadership, consistency, and signs of stability from the local, provincial and federal governments who have a tendency to take different approaches to setting standards (e.g. security standards), and building systems. From SME associations and the National Liberal Caucus Economic Development Committee are recommendations for beneficial tax treatments on e-business related SME expenditures, similar to those given for Y2K in 1999.

Workforce skills are well recognized as being an essential element to ereadiness (Jutla et al 2002a, McConnell 2001, International Development Center 2001, European Union 2001). Canada also uses the International Computer Driving License curriculum for professionals and teachers to upgrade IT skills. In a train-the-trainer program, the Student Connection Program (SCP) hires and trains university and college students to act as Business Advisors on Internet and e-business to SMEs.

Government Online (2002) or "GoL" is Canada's naming of egovernment, another key factor in an e-readiness strategy. All provinces are mandated to place a large percentage of services online to all citizens by 2004. Behind the scenes, the Canadian government has enabled a network of government departments and agencies that service SMEs to co-ordinate and exchange research projects, experiences, and programs as an initiative under its "e-Business Growth Strategy." To complement the public sector activities, a Canadian e-Business Opportunities Roundtable (eTeam, 2002) comprising of mainly private sector representatives was formed in mid-1999 to "accelerate Canada's leadership in the digital economy." Six subteams led by Roundtable members form the e-Team Canada umbrella.

Digital collections for organized content focused on culture, science, geography, and so on can be found at collections.ic.gc.ca/. Most of the collections are created within a Youth Employment program where students aged 15-30 create the web sites using content from Canadian museums, and other archives. Canada's efforts at organizing content for SMEs are best found in the strategis (http://strategis.ic.gc.ca) web site - a site that provides 
databases of information for trade, supply, export, legal research, business financing, patents, matches on private sector and university-based expertise to name just a few.

The subteam for the SME e-Business Adoption Initiative, created under the Canadian e-Business Opportunities RoundTable e-Business Acceleration team to encourage Canadian SMEs into becoming sophisticated users of ebusiness technologies, has added content to the strategis.ic.gc.ca/ebizenable site. The latter site addresses breaking barriers to e-business adoption. The March 2001 report (Ivis 2001), from the SME Adoption subteam, streamed the top-level barriers inhibiting SME e-Business adoption into 4 categories: information and education, costs and benefits, e-business resources, and security. The report recommends an assessment of the resources and materials available from and to the public and private sectors, as well as the creation of an SME eBusiness Toolkit. According to the Ivis (2001), "SMEs not using the Internet cite ROI and cost as primary inhibitors, those using the Internet cite the lack of e-business strategy as the barrier, and those implementing transactional capability say that security is the barrier." Lack of leadership and managerial skills are also commonly identified business success barriers in SMEs in Canada.

One recommendation from the subteam for the SME e-Business Adoption Initiative is for the creation of a toolkit of resources for helping the SMEs to overcome these barriers. In October 2001, the "toolkit" was provided in the strategis collection (EbizEbable, 2002). While the content on strategis is generic to all SMEs, a great deal of localization and syndication is still needed to enable the effectiveness of the toolkit throughout disparate regions in Canada.

Results of the combined efforts of government, and private sector show that approximately 630,000 of Canada's one million businesses are now online. Small and medium enterprises employ 6 out of 10 working Canadians. The majority of Canadian businesses are very small. $97 \%$ of the one million Canadian businesses have less than 50 employees. $78 \%$ has less than 5 people. Thus the growth of the SME sector is extremely important to the Canadian economy.

The numerous multi-level and fragmented initiatives and support sites described in this section provides the foundation and backdrop for development of a strategy to support rapid e-business adoption in SMEs in Atlantic Canada. Next we will provide a short description of the business environment in Atlantic Canada. 


\section{ATLANTIC CANADA: PROBLEMS AND OPPORTUNITIES}

Atlantic Canada comprises 4 out of 10 of Canada's provinces: Nova Scotia, New Brunswick, Prince Edward Island, and Newfoundland. This region represents only $6 \%$ of the national economy - even with over $8 \%$ of the population. As the Atlantic Provinces' private sector remains underdeveloped, in comparison with other parts of Canada, e-business awareness levels are lower than the national average. The Atlantic Provinces have lower levels of human capital that are working in greater numbers in smaller businesses than other regions (ACOA, 1997). Additionally, while fully $49 \%$ of the Atlantic workforce is employed in areas where the capabilities of ebusiness and knowledge economics (StatsCan 1996) are directly applicable, there is little of the expected development in e-business technologies. The SMEs in Atlantic Canada have, generally speaking, been slower to adopt new technologies than the remainder of Canada. The latest Canadian (CFIB, 2000) Internet survey of SMEs states that "while Nova Scotia has a high Internet penetration rate ( 73 percent), the prevalence of e-businesses $(26 \%)$ is below the national average.

While businesses in other regions of the country are investing in the benefits of e-business, most Atlantic Canadian SMEs are not. There are several reasons for this relative regional disparity within Canada. They include (Weatherbee, 2000):

a) The 'high-knowledge' industrial sectors are currently the fastest growing sectors in Atlantic Canada representing an opportunity for learning and information exchange horizontally across sectors;

b) One of the highest per capita density of degree granting institutions in the continent, situated particularly within Nova Scotia, representing an untapped wealth of human capital and expertise that is not being utilized;

c) Regional cost advantages within the 'knowledge management' sector, as well as quality of life benefits which could be leveraged to gain a competitive advantage for the development of this sector within the region; and

d) A strategic presence at the midpoint between North American and European markets which presents an opportunity for e-business valueadded activity for both knowledge and supply chain activities.

The region also has a number of potential opportunities that may be exploited in the arena of e-business. These include:

a) The continued forecasted growth and importance of information/knowledge based industries. This trend is forecasted to continue for the next two decades (APEC, 2000) and investment in this 
area will produce higher returns on investment than current resource based industries while growth will outpace traditional manufacturing sectors;

b) Competitive potential for non-geographically reliant value-added activities as geography becomes less of a limitation within knowledgebased businesses or through utilizing e-business tools;

c) An information and communications infrastructure on par with the remainder of the country which can provide ready access to business within the region and provides a competitive foundation that may not be available to competing organizations within the balance of the continent or internationally;

d) A large potential for university and private sector joint ventures leveraging the density of learning and educational institutions within the region; and

e) The ability to take advantage of the growing clusters such as the Halifax Regional Municipality 'Industrial Cluster' (ACOA, 1997), the Fredericton-Moncton corridor or the Saint Johns cluster; which have sufficient critical mass to support knowledge exchange, a learning environment and horizontal synergy within and across sectors.

\section{CLEAR AND ITS SUPPORT STRUCTURE}

CLEAR is a Pan Atlantic strategy to accelerate e-business adoption in the over 12000 SMEs in Atlantic Canada. The CLEAR concept and its underlying partnership-based model are initially detailed in (Weatherbee, 2000). CLEAR proposes the setting up of an innovative knowledge-sharing mechanism and formal partnership network among various levels in the education, government, and private sectors in the region. It intends to play a coordinating role in creating a value web that will increase knowledge and innovation output, raise business and IT-based skill sets, promote egovernment practices in all municipalities, and facilitate strong linkages between innovation research in universities and SMEs.

Initial services from the CLEAR implementation will include:

1. Coordination and hence alignment of regional research to create and transfer innovation to SMEs;

2. Aggregation of resources, capabilities, and capacities of public sector research infrastructure, human capital from local and international researchers, government agency employees, SME association employees, and private sector employees;

3. Creation of new channels for communication among stakeholders for value creation; 
4. Creation of new social capital for SMEs. Social capital is a construct essential to the success of innovation networks (Cooke, 1999);

5. Peer-reviewed research grant funding mechanism for research projects targeted at breaking down the barriers to e-business adoption in SMEs as well as projects targeted at creating business process innovations in partnership with SMEs;

6. Development and validation of new methods and models for e-business adoption in SMEs;

7. Development of new business processes, methods, technologies to support SME needs;

8. Development of new databases to support reduction of barriers to ebusiness adoption and follow-through;

9. Self- and external measurement of service success;

10. Knowledge sharing and knowledge protection mechanisms such as sophisticated intellectual property proposals;

11. Knowledge transfer of non-codifiable knowledge;

12. Alignment of regional standards to national standards;

13. Facilitate the creation of Pan-Atlantic standards for trust and regulatory infrastructure;

14. Connect SMEs with funding mechanisms; and

15. Strengthen the ability of SMEs to absorb new technologies

In a nutshell, CLEAR's mechanisms will be designed to aggregate and align capabilities, capacities, and resources in Atlantic Canada for maximum value creation. The CLEAR network of partnerships, referred to the CLEAR network for brevity in the rest of this paper, is built on consensus through leadership and sharing of a common vision. In practice, the leadership and original concept for CLEAR emerged from a business school in Atlantic Canada. The leaders shared their vision with other business schools in each of the 4 Atlantic provinces, provincial and federal government agencies, community colleges, law and computer science institutes, SME associations, local boards of trade, government and university-managed business development centres, community colleges, private sector, and SMEs. One major private sector partner is Aliant Inc., the regional telecommunications company, and one of only 4 major businesses in Atlantic Canada. One example of a SME association that has joined is the Canadian Federation of Independent Businesses. International partnerships are currently being sought.

Numerous research articles in Etzkowitz and Leydesdorf (1997), document the importance of the third role of universities, that of industrial participation, for transfer of knowledge and innovation to SMEs. Strengthening linkages between university and industry will increase 
innovation transfer. Interlocking and other necessary factors for creation of innovation include shared vision, leadership, management skills, availability of funding, and a high degree of partnerships to name a few. Furthermore, many researchers (e.g. Cohen and Levinthal, 1989, Fountain 1998, Cossentino 1996) show the importance of social capital to SME ability to innovate and eventual success. Social capital is created in a rich partnership model such as that on which CLEAR is built. Social capital involves tangible assets of goodwill, fellowship, sympathy, and social intercourse (Hanifan 1920), and social relationships to promote or aid in the development of valued skills and characteristics (Loury 1977).

Opening communication channels across partnership boundaries often causes acquisition of new skills by participating professionals. It also costs in terms of participating employees' time to manage and service the channels. According to Cooke (1999) "communicating across firm and cultural boundaries (as within a rich partnership network) is a profoundly social, interactive process where great care, attentiveness, and patience must be developed." It is area where government and universities with a history of facilitation, partnership and slow, careful decision-making have experience.

The proposed structure of CLEAR is outlined in the organization chart shown in Figure 1. CLEAR consists of five organizational components that are discussed below.

\section{CLEAR Organizational Structure}

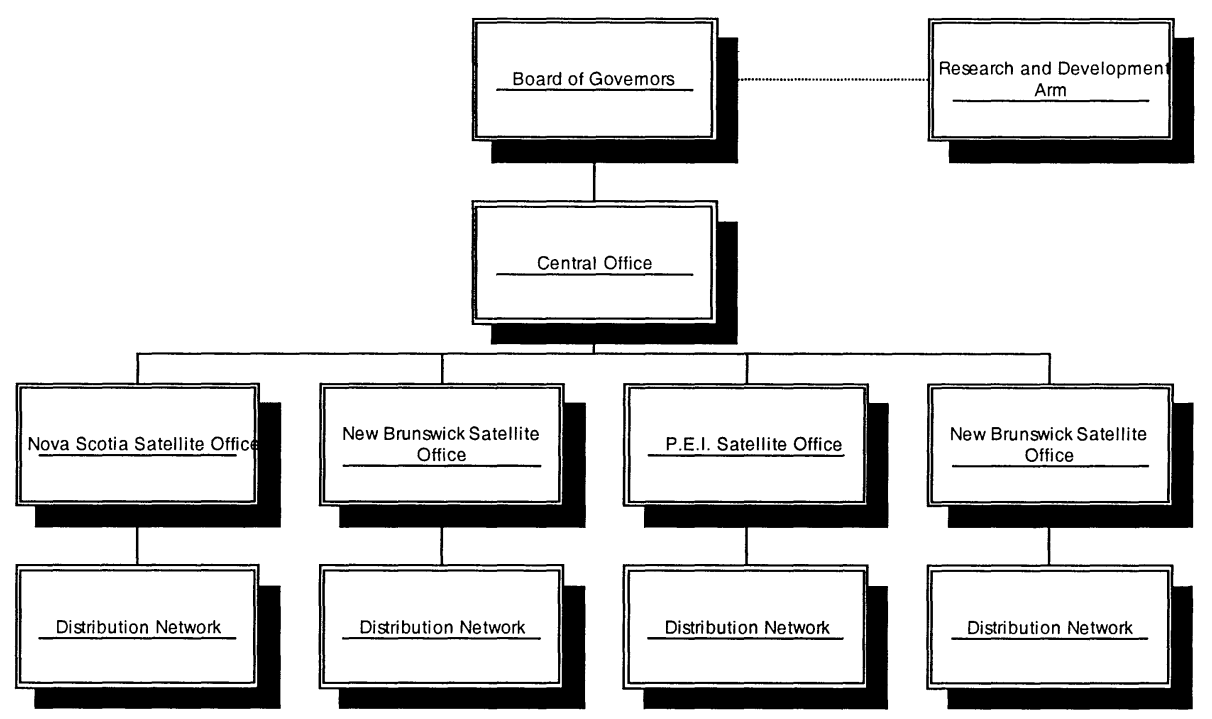

Figure 1. CLEAR organizational structure 


\subsection{Board of Governors}

A board of governors will provide oversight for CLEAR. The board will include representation from institutional partners, business representatives and government partners from the federal and provincial levels. The role of the board is to provide strategic direction, resource allocation, and accountability.

\subsection{Central/Head Office}

CLEAR will include a central implementation office, which will be responsible to the board of governors for the operations of CLEAR. The role of the central office will be to create and execute the overall strategy for CLEAR, aggregate and align cross-provincial efforts, coordinate research \& development initiatives, and coordinate the development of online and offline content. CLEAR's central office is responsible to the board of governors for the operations of CLEAR. The office consists of a full-time director of operations, a full-time director of communications, a stipended strategy director and a stipended research director from the lead agency's business school. The role of the central office will be to implement the overall strategy for CLEAR, coordinate research \& development initiatives, and coordinate the development of online and offline content, and the development and growth of partner participation and delivery mechanisms.

\subsection{Research and Development Arm}

The research and development arm contains the set of Atlantic Canada researchers working on projects that are targeted to breaking the e-business barriers for SMEs. The value of the R\&D component is in its knowledge and innovation creation, and innovation building capability and capacity. A research director at the head office's R\&D arm will coordinate research efforts for all the provinces. Appointed lead researchers for each province will report to the research director. 4.4 Provincial Satellite Nodes.

CLEAR will establish a physical presence, or satellite office, in each of the four provinces. It is anticipated that these will be hosted by the business schools of institutional partners This is a strategic association since content and enabling tools developed by researchers are critical to the success of 
CLEAR, and it creates a strong linkage between innovation from public research and SMEs. Additionally, the largest problem facing SMEs in developed countries is the absence of sufficiently organized content. Even the most connected countries still need to facilitate the organization of content around verticals and clusters for SME participation and aggregation. Online collections are important for lifelong learning, and the weaning from dependencies on more expensive off-line services.

The role of the satellite offices will be: (1) to provide a coordination role in SME e-business initiatives within the satellite's province to create content and enabling tools for the SMEs (2) to bring potential partners together and to promote SME clustering (3) to serve as a direct channel for gathering input and feedback from SMEs and other provincial bodies back to CLEAR and its researchers, and to transfer knowledge/innovation back to the SMEs (4) to input into the content of the field consulting services via a distribution network to SMEs within their province (5) to deliver training and content to the provincial distribution network

The Sobey's Business School at Saint Mary's University, the Electronic Commerce Centre at the University of New Brunswick at Saint John, the PJ Gartner School at Memorial University, and business school at UPEI are the recommended hosts in their respective provinces. Each satellite office will include a satellite director, and 2 operations staff, (one dedicated to communications and the other operations), with the exception of the PEI office (requires small geographic coverage), which will have one operations staff. Each satellite office will also have a lead researcher who will supervise in the development of applied research and content of specific relevance to the local environment for the host province.

\subsection{Link and Distribution Network}

The link and distribution network is the mechanism for CLEAR's delivery of localized e-business services directly to the SMEs, and for delivery of SME needs to the university and public sector researchers. The precise structure of the distribution network across the region will depend upon the structure of partners/networks as developed by the satellite offices. It is anticipated that provinces will select different delivery structures, depending on existing infrastructure. The University Business Development Centre network has already been identified as the distribution partner in Nova Scotia, and the New Brunswick Community College system as the partner in New Brunswick. Holland College in UPEI and the community college system in New Foundland are proposed for PEI and Newfoundland respectively. The value of these delivery partners are that (1) they have the trust of the SMEs in that they are already familiar with the SMEs' bankers, 
lawyers, and accountants, (2) they have excellent geographic coverage of the whole Atlantic region, and (3) they already act as consultants for business services to many SMEs. For these reasons they are perfect partners to provide the mentorship and handholding required for effective acceleration of movement of e-business practices into SMEs. In Nova Scotia, particularly there is an advantage for receiving SME needs into university research, since the university business development centres are acting as the link and delivery channel. Many of the Nova Scotian business development centres have provided very low cost services (sometimes free services when there is a lot of student involvement) to small businesses in the region. It has built a lot of goodwill for the universities in the SME firms. Services include writing business plans and developing strategies.

\section{POTENTIAL BARRIERS AND RISKS FOR CLEAR}

There are number of barriers and risks facing CLEAR. Obtaining funding for CLEAR will be a major barrier, especially in the aftermath of the meltdown of the dot com stocks. Governments, like SMEs, are also unsure of calculating return on investment, even though the concept may make sense. Because of CLEAR's scale, funding will come from many sources and infused at different stages. Mismatch of initially identified funding requirements and projected timelines with actual requirements and completion times can emerge. Management of the numerous applications for funding and providing reports to funding bodies with diverse accountability standards could be onerous. Once funding is obtained, the risk of limited commitment on the parts of faculty members at the various business schools can prevent success. There is a risk that incentive schemes for faculty members working in CLEAR may conflict with the usual reward structures for a university faculty employees. The mismatch between university careful and studied cultures and the SMEs needs for quick and sometimes dirty solutions can possibly lead to friction and dissatisfaction for the partnerships. Careful management of expectations among partners will be necessary.

The cause of most economic development schemes that fail in Atlantic Canada has been identified as a lack of a good business plan. Such a plan needs to cover aspects of identification of critical success factors and priorization of tasks. Should insufficient funding be a problem, critical positions should less likely be cut with a reasonable business plan. 


\section{RELATED WORK}

The CLEAR strategy requires (1) the building of a strongly-linked collaborative network, or "network of networks" for coordination and alignment, (2) instituting knowledge management processes between universities and SMEs, and (3) complementary infrastructure (technological, human, regulatory, trust, financial, content, and e-government leadership). On surveying strategies with similar goals in various countries, we find that some have two separate strategies to address the above points; while some combine all three in one innovation strategy. For example, Germany has INSTI (www.insti.de), a 5-year collaborative project designed to facilitate effective technology transfer between research institutions and industry. According to INSTI's website, " 32 mainly private enterprise partners from the invention and patent sector have joined the INSTI Project: patent attorneys, regional patent information centres, information brokers, regional inventor support centres, business consultants, technology agencies and transfer agencies of higher education institutions and research institutes."

Countries start from different places when creating strategies for strengthening links between university research and SMEs. For example, Europe has millions of SMEs; in contrast Canada hosts a total of one million businesses, with under 50000 in Atlantic Canada. Thus one reason that European strategies will differ will be due to disparities in scale. The EU programme titled "innovation and participation of SMEs", launched in 1999, aims to "stimulate, disseminate, and exploit the results of research, in particular for the benefits of SMEs (CORDIS, 1998)". It is under the umbrella of the Fifth Framework programme (coordinating body) and complements other specific $5^{\text {th }}$ Framework programmes and, coordinates schemes such as CRAFT, with its own distinctive initiatives. CRAFT is a program wherein SMEs can outsource co-operative research to university institutions. The overall aim is "to improve the economic and social impact of research, by ensuring better dissemination and exploitation of its results, and encouraging the transfer and dissemination of technologies. "(CORDIS, 1998).

The European "Go Digital" initiative is aimed squarely at SMEs for adoption of e-business. The European Commission claims that e-commerce in the European Union is hampered by lack of consumer trust. $66 \%$ of small companies have Internet access, but only $6 \%$ of small businesses transact business online in real-time. The most important influences on SMEs' future uptake of e-business awareness and opportunities may come from the roles of associations and governments.

In the Netherlands, partnerships among private and public sector firms, institutions, and associations is brought together in the Electronic Commerce 
Platform (www.ecp.nl) to accelerate innovation creation and use. The Dutch Syntens is a business innovation network for small businesses that promotes the adoption of technologies in SMEs.

In late 1998, in Singapore, a national level Electronic Commerce Coordination Committee (EC3) was formed to manage e-readiness efforts. The Local Enterprise Electronic Commerce Programme has to-date assisted more than 500 local enterprises in their e-readiness efforts, mostly on a costsharing basis.

\section{SUMMARY AND CONCLUSIONS}

Proposed in this paper are university business school involvement, and an accompanying formal infrastructure to support the CLEAR strategy, that facilitates widespread diffusion of e-business practices, processes, and opportunities in SMEs in Atlantic Canada. Working with government agencies, other disciplines, and various SME stakeholders, business schools in universities can advise, collaborate, and provide services to build the environment for aggressive e-business adoption in SMEs, and hence grow the digital economy.

Copying another's successful innovation network is not an instant recipe to success (Novakovic and Sturn 2000). Localization factors, such as the structure and characteristics of national R\&D systems including incentives, are critical success factors. To this end, we illustrate a novel strategy for business schools in universities, in the Atlantic Canada setting, to work together to impact on the SME adoption rate of e-business in their regions. CLEAR builds on other existing and growing infrastructure, in terms of, communications and information, human, content, e-government, regulatory and trust, knowledge and innovation infrastructure, and existing distribution networks. Countries with similar problems and opportunities as those found in Atlantic Canada may benefit from examination of the CLEAR strategy, and perhaps contribute new ideas to the CLEAR work.

Even though, e-business research is being heavily quoted from the IS (information systems) and marketing fields (IFIP84, 2002), in many countries, such as Canada, business research is comparatively under-funded in the national R\&D systems (Renaud, 2001). CLEAR defines infrastructure, pro-active roles and ownership of tasks, and opportunities for researchers from business sub-disciplines such as management (including human resources, SME), economics, accounting, marketing, management science, finance, and information systems to contribute to the digital economy. In addition to the potential positive impact that the business researchers can 
have on SMEs, cheaper and quicker means of identifying needs and collecting data (e.g. through partnership with SME associations) becomes apparent.

\section{REFERENCES}

Accenture (2001). Rhetoric vs. Reality - Closing the Gap. (AC111 30/03/01 6:27 pm). Second Annual Survey of e-government. Available at www.accenture.com $/ x \mathrm{~d} / \mathrm{xd}$.asp? it=enWeb\&xd=Industries\%5CGovernment\%5Cgove_study.xml. Viewed February 2002.

ACOA (1997). Prospects for Growing Knowledge Based Industrial Clusters in Atlantic Canada. Atlantic Canada Opportunities Agency Report. Ottawa: Nordicity Group Ltd, Syntel Consulting Inc (Halifax), \& Horizons Consulting Ltd. (St John's), 31 July 1997.

APEC (2000). Our University Students: The Key to Atlantic Canada's Future. APEC and AAU Report. January 2000.

Barre, R. and Guinet, J. (2000). Benchmarking industry science relationships. A publication of the Federal Ministry of Education and Research, and the OECD. Available at www1.oecd.org/dsti/sti/s_t/inte/prod/tip2001 barre.pdf. Viewed February 2002.

CA3 (2002). Advanced Networks. Available at www.connect.gc.ca/en/ar/1002-e.htm. Viewed January 2002.

CANARIE (2002). Canada's Advanced Internet Development website. Available at www.canarie.ca. Viewed January 2001.

CAP (2002). Community Access Program: Connecting Canadians. Available at cap.ic.gc.ca/english/5000.shtml. Viewed January 2002.

CFIB (2000). E-Business Update: Internet Use among Small and Medium Sized Firms. Canadian Federation of Independent Businesses Survey. August 2000.

Cohen, W. and Levinthal, D. (1999). Innovation and Learning: The Two Faces of R\&D. The Economic Journal. 99, 569-596.

Cooke, P. (1999). Small firms, social capital, and the enhancement of business performance through innovation programs. Small Business Economics. 13(3), 219-234.

CORDIS (1998). Introducing the "Innovation and participation of SMEs programme - the key to making the most of the Fifth Framework Programme. European CORDIS database. As of 9 June 1998.

Cossentino, F., Pyke, F. and Sengenberger, W. (1996). Local and Regional Response to Global Pressure: The Case Study of Italy and Its Industrial Districts. International Institute for Labour Studies.

Craig, J. and Jutla, D.(2001), eBusiness readiness: a customer focused framework. Boston: Addison Wesley.

EbizEnable. (2002). SME e-business Information Toolkit. Available at strategis.gc.ca/SSG/ee00240e.html and strategis.gc.ca/sc_indps/ebiz/engdoc /homepage.php. Viewed January 2002.

ECPlatform. (2002). Electronic Commerce in Nederland. Available at www.ecp.nl. Viewed January 2002.

ETeam. (2002). Electronic Commerce in Canada. Available at "e-com.ic.gc.ca /eteam/mission.html. Viewed January 2002.

Etzkowitz, H., and Leydesdorf, L., (eds.) (1997). Universities and the Global Knowledge Economy, A Triple Helix of University-Industry-government Relations, eds. London: Printer. 
EUScoreboard. (2001). The European Innovation Scoreboard: October 2001. Available at www.cordis.lu/innovation-smes/scoreboard/. Viewed December 2001.

Fountain, J. (1998), Social Capital: A Key Enabler of Innovation. Investing in Innovation. L. Branscomb and J. Keller (eds.), Cambridge: MIT Press, 85-111.

GoL (2002). www.gol-ged.gc.ca/index_e.asp. Viewed January 2002.

Hanifan, L. (1920). The Community Center. Boston: Silver, Burdette and Co.

Hosmer, L.T. (1995). Trust: The connecting link between organizational theory and philosophical ethics. Academy of Management Review, 20(1), 379-403.

Hull, D. (2000). Connecting Canadians: an agenda for the knowledge economy and society. Information Highway Applications Branch of Industry Canada, Distinguished Lecture Series. Halifax: Dalhousie University.

IEI (2000). Information Economy Initiative. Available at www.gov.ns.ca/govt/accountability/ tssaccrpt01.pdf. Viewed February 2002.

International Development Center (2001). Harvard University: International Development Center e-readiness guide, Available at www.readinessguide.org. Viewed January 2002.

IntIsland (2000). IT2000: Realizing an Intelligent Island. Available at www.sone.gov.sg/overview/it2k01.html. Viewed January 2002.

ICDL (2002). International Computer Driving License. Available at www.icdl.org.za. Viewed January 2002.

IFIP84 (2002). Call for papers - Seeking success in e-business: a multi-disciplinary approach. Available at www.ifip2002.cbs.dk/. Viewed February 2002.

Jutla, D., Bodorik, P. and Dhaliwal, J. (2002a). Government Support for e-Readiness of Small and Medium Sized Enterprises. Hawaii International Conference on Systems Science. IEEE: e-Governance track.

Jutla, D., Bodorik, P., and Dhaliwhal, J. (2002b). Supporting e-Business Readiness of SMEs: Approaches and Metrics. Internet Research Journal. In Press 2002.

Jutla D., Bodorik, P., Weatherbee T., and Hudson B. (2002c), e-Government in Execution: Building Organizational Infrastructure. European Conference on Information Systems, ECIS, Gdansk, June 6-8, 2002.

Lefebvre, E. and Lefebvre L.A. (2000). SMEs, Exports, and Job Creation: A Firm Level Analysis. CIRANO and Polytechnique de Montreal. Available at strategis.ic.gc.ca/SSI/ra/op26_e.pdf. Viewed February 2002.

McConnell International LLC and WITSA (2001). Ready? Net. Go! Partnerships Leading the Global Economy. Available at http://www.witsa.org/papers/e-readiness2.pdf Viewed February 2002.

Novakovic, M. and Sturn, D. (2000). Start-up on Campus - European models for the stimulation of academic spin-offs. Available at www.tig.or.at/bilder/45.doc. Viewed February 2002.

Porter, M. (2001). The Global Competitiveness Report 2001-2002. World Economic Forum. Oxford, 2002.

Renaud, M. (2001). Presentation on SSHRC New Economy Initiative, Saint Mary's University, Halifax, 20 April 2001.

SchoolNet. (2000). SchoolNet's On-line Connectivity Survey: Final Report. Available at www.schoolnet.ca/home/e/Research_Papers/Research/SchoolNet_Research/Final_Survey _Report_2000(English).htm. Viewed May 2001.

StatsCan. (1996). Statistics Canada Labour Force Report, 1996 Census, available at www.statcan.ca/english/Pgdb/People/Labour/labour45a.htm, Viewed January 2002. 
VolNet. (2002). Connecting voluntary organizations to the Internet. Available at www.volnet.org/. Viewed January 2002.

Weatherbee, T.G. (2000). A Proposal for A Centre of Learning: for e-Business Awareness and Resources - (CLEAR). Report FMS\#01-01. Saint Mary's University. 